\title{
Psychosexual bodywork: should we refer our patients, and if so why?
}

\author{
Susan Quilliam
}

Freelance Writer, Broadcaster and Agony Aunt, Cambridge, UK

\section{Correspondence to}

Ms Susan Quilliam;

susan@susanquilliam.com

Received 16 August 2011 Accepted 18 August 2011

\section{Background}

The setting was central London, February 2011. The event, hosted by the British Society of Sexual Medicine (BSSM), was an excellent workshop on vaginismus and sexual pain. Participants had discussed a presented case study, and had offered a variety of treatment suggestions from exploring the patient's psychological history, through questioning her relationship satisfaction, to suggesting she use dilators. Then came the (metaphorical) hand grenade.

"Why don't we use bodywork?" said a voice from the back. A palpable shiver ran round the room. I pricked up my ears - did I sense a controversy here? I did. The suggestion made by the delegate was indeed that the patient be encouraged to try 'hands on' therapy - not just talk about her problem nor retreat to the privacy of her own home to do exercises, but work with the therapist in a way that might include sexual touch. The delegate in question didn't seem to have horns and a forked tail, but nevertheless there was a strong sense from the audience that what was being suggested was heresy.

Being the non-conformist that I am, I was immediately fascinated and before the day was out, had arranged an interview with said delegate and three of her colleagues. I wanted to clarify directly what was being suggested. Did they really mean that a psychosexual therapist should touch a client? If so, why? And, how did it work?

\section{Why bodywork?}

In the event, my four interviewees were despite the sharp intakes of breath at the BSSM - the exact opposite of demonic: delightful, genuine and lobbying professionally for the inclusion of client-controlled touching as at least an option in psychosexual therapy.

I began with the basic question, raised by the interviewees themselves. Why should a Journal reader refer their patient to a psychosexual bodywork therapist? The given answer was simple - because "it offers a different framework and a different approach", and because that approach works. Plus, if medication and talking therapy alone have not achieved results, bodywork often can; some clients do "need the particular way forward that bodywork offers".

A strong claim. And I was as yet still unclear precisely what we were talking about here. Does 'bodywork'. mean talking, massage, breathing, clothes on, clothes off, holding hands, touching genitals?

The answer was Yes - subject to constant negotiation between client and therapist, all of the above could be part of a bodywork session. The list I gathered from my interviewees included many techniques that any good psychosexual therapists might use: visualisation; breathing exercises; painting; writing; fantasy; sex education on a broad scale; information on anatomy; information about the variations in anatomy; information about the sexual act; discussion of desires, discussion of boundaries. myth-busting; self-esteem raising; body image work; and so on.

That was the first half of the list. The second half included techniques that most psychosexual therapists would not use. Not only talking about the client's body image, but the client undressing in front of the therapist. Not only discussing what sort of massage the client likes, but the psychotherapist delivering same. Not only exploring the client's fears around being touched sexually, but the therapist massaging the client's genitals.

This second list is so clearly outside the current normal session range that my next question had to be about the rationale. Why include these very intimate possibilities in a professional therapist-client relationship? 


\section{Bodywork benefits}

The answer I received from all four interviewees was clear: while many patients benefit from interventions drawn from the first list, sometimes they need techniques drawn from the second list. Sometimes, given ethical boundaries and full consent, I was told, there is a need to give the client not just new insights but new experiences. Of course, this suggestion in itself is not new - 'sexual healing' has been done for millennia, and even in our present era, in the 1930s, Wilhelm Reich used physical touch to release trauma in the body the result for clients was reportedly a hugely increased ability to feel sexual pleasure.

"Experiential learning is helpful and not harmful; sometimes you need to explore what might come up in a relationship by simply doing it."

All my interviewees showed a passionate commitment to the benefits of bringing such sexual awareness into the therapy room: "It shouldn't be this terrifying monster that we never speak of". Plus there was a real belief that practical action, in addition to talk therapy, "normalises ... educates ... helps the client to work through issues". There was absolute conviction that in this situation, experiential learning was helpful and not harmful; sometimes you need to "explore what might come up in a relationship by simply doing it".

So consider the patient with vaginismus mentioned at the start of this article. She may indeed need to talk about her feelings and sensations, may need to practise inserting a dilator. But she may also, claim bodywork advocates, benefit from being touched by the therapist and from exploring her reactions to that touch. Crucially, she may also benefit from saying a firm "No" to touch and having that "No" respected and obeyed, rather than needing to "give in to social or partner pressure" as she may have had to do in her relationships up to now.

Consider too a man whose erectile difficulty is based on a fear of needing to perform. He may indeed need to explore his past erectile failures, and may need to do sensate focus exercises. But, my interviewees argued, he may also benefit from having his pelvic area and penis gently massaged by the therapist while he realises that in this situation it's fine not to have an erection, all the while being told and telling himself that "there is no need for performance". He may come to realise that he's just as valid a person without an erection, take that validation back to his own partnership, and thus grow in confidence and regain his ability to achieve an erection.

Does psychosexual bodywork automatically involve touching? Absolutely not, I was informed. Every client has an introductory assessment session where the therapist explores what approach would suit - some clients simply aren't ready for or into bodywork. Many clients simply need to talk - the key is that whatever happens in a session is centred around education: learning to accept pleasure, learning to feel in control, learning to move beyond difficulties, learning to face and heal concerns and worries.

\section{Patients who can be helped}

Which patients would bodywork be most suitable for? My interviewees had had a range of experience with almost every sexual problem, but there also seemed to be a common underlying theme: many patients were presenting with a loss of connection with their body, which often created a resistance to sexual contact.

For example, post-surgery patients whose body esteem has plummeted or post-birth patients whose ability to feel sexual has disappeared. Patients who've been abused and whose defence is to anaesthetise all arousal. Patients who panic when faced with the possibility of being naked, of being touched, of touching. Patients who've unwillingly accommodated their partners' desires for far too long and whose defence is to close up, to hold back from erection, to be unable to climax, to climax too soon, to switch off desire.

"The key is that whatever happens in a session is centred around education: learning to accept pleasure, learning to feel in control, learning to move beyond difficulties, learning to face and heal concerns and worries."

In response to these issues, what my interviewees offer at the centre of their work is two-fold. First, ways of solving the loss of connection with experiences of reconnecting with the body, whether through talking, showing, being touched or touching. And second, as mentioned above, an experience of being totally in control of that process. The client can say "No" and in contrast to many relationship situations - the therapist will always not only respect but also validate that. "If the client says how they want to be touched - how light, how heavy, how shallow, how deep, when to start, when to stop - then the experience of having control can in itself be the solution."

Equally, the client may well say "Yes", but the therapist will also register and obey any sign that 'consent from the body' is lacking. If the vagina doesn't open, if the clitoris doesn't harden, if the penis doesn't erect, then that's a message from body to conscious awareness and needs to be taken seriously. A huge part of the psychosexual bodywork that my interviewees practise is about helping the client become aware of such messages, take them seriously, and act on them. (It struck me that this is a lesson that might to good effect be taken on board by everyone, therapy client or not; we so often dismiss sexual responses as being just from the body when in fact they are a mental and emotional communication too.)

\section{Risks and safeguards}

My interviewees were not professionally naive. They admitted that bodywork can present challenges just as any client-therapist relationship - or indeed any professional relationship - can. High on the list of client dangers is "going too far too fast in order to please - we 
need to be very alert to that", as well as classic transference of client 'falling in love with' the therapist, and that transference needing to be worked through when the therapy work is done.

What protection is offered? Typically for all therapy, my interviewees stressed that client and therapist must agree on what will happen, and then negotiate continuously to make sure that the client is comfortable with that agreement. Unusually for therapy, they also suggested the setting up of clear 'safe words', which can be used to stop any activity; the welcoming of a chaperone for the client; and the encouragement for clients to share their session experiences with a friend, psychotherapist or referring practitioner to "avoid the secrecy". One of my interviewee's websites has a charter so that prospective clients knew clearly and ahead of time what their rights are.

This charter also protects the therapist. What if a client mistakes therapy for sexual interest? As protection, the training for psychosexual bodywork that my interviewees described was long and rigorous (several postgraduate diplomas in psychosexual counselling and psychotherapy) and supported by memberships of various professional bodies, among them the Independent Practitioners Network. All are in supervision, have peer supervision, take ongoing continuing professional development courses and are in personal therapy. "We have in place as many checks as we can to make it a safe environment for the client and for ourselves.”

That said, the wider world often doesn't acknowledge the ethical basis of bodywork. One of my interviewees was recently profiled in a major British newspaper which raised the issue of whether psychosexual bodywork was sex work, and bodywork therapists sex workers. My interviewees answered: "We're not working off a menu from which the client chooses what they desire; we're taking the client through a process to help them reach a goal. It's very different".

\section{Final thoughts}

At this point, regular Journal readers will expect a strong pro or con from me on the issue in hand. But in fact, I think the question is much more complex than that.

I totally agree with contemporary concerns about therapist-client boundaries, but I also feel that by acknowledging 'the elephant' of sexuality in the counselling room, in a way that much therapeutic training rarely does, bodywork practitioners could well be much less likely to transgress such boundaries.

On the other hand, while I love the idea of teaching clients to truly consent to sexual activity in a way that they previously may never have done in their relationships, I do question whether, given therapist-client dynamics, congruent client consent to therapeutic touch is ever really possible.

Conversely once more, I deeply believe that psychosexual therapy can be wonderfully effective without any physical contact. But I do wonder whether, in a different climate and a different culture, the treatment of sexual problems without any element of physical contact would be seen as illogical and absurd.

\section{Two case histories}

Sally, a 50-year-old woman brought up in a strict Christian environment, and who had not had sex before marriage, had never allowed herself to be orgasmic. She had worked in talking therapy for a long period before trying bodywork, and so it took just one session of genital touching to become orgasmic - and then to allow intimacy of all kinds into her life. She now reports dating again after 31 years.

Richard, a 40-year-old man, was on testosterone treatment for erectile dysfunction but was told the problem would be with him for life. He found psychosexual bodywork by accident, and benefitted from sessions of gentle penile massage, which have brought his erections up to $70-80 \%$ of what they might be expected to be.

\section{If you are interested...}

Psychosexual bodywork therapists are happy to receive referrals from any health professional or therapist who feels a patient may benefit from bodywork.

Therapists work in conjunction with the medical treatment a patient is already receiving; equally if a body work practitioner receives a client whom they think needs medical treatment then they will refer on.

An introductory assessment session identifies if a patient is suitable for and ready for the bodywork approach. Subsequent sessions may last longer than the classic therapeutic 50 minutes, often for several hours. A typical session costs $£ 60-£ 80$ per hour for talking work and $£ 100$ per hour for bodywork.

\section{Contact details}

The therapists interviewed for this article are happy to talk to any health or therapy practitioner interested in exploring how patients can best use psychosexual bodywork.

\section{Competing interests None.}

Provenance and peer review Commissioned; internally peer reviewed.

\section{THERAPIST CONTACT DETAILS}

Mike Lousada - www.mikelousada.com; e-mail: mike@ mikelousada.com; mobile: 07739260600

Sarah Robinson - www.sexandrelationshipcoaching.com; e-mail: sarah@un-limited.org; mobile: 07811169508

Katie Sarra - e-mail: katie@katiesarra.com; mobile: 07540 571745

Clare Walters - www.clarewaltersbodywork.co.uk; e-mail: clarewaltersbodywork@gmail.com 